\title{
Do different cultural values affect the excess return of
}

\section{sin stocks?}

\author{
Michelle Amory ${ }^{1,2}$
}

\begin{abstract}
Several studies have demonstrated that sin stocks have different characteristics in comparison with other stocks. However, previous research that examines sin stocks has generally assumed that countries are similar in their stance towards sin stocks or that other nations are similar to the US and have some degree of disapproval of sin stocks. This study introduces a new model and shows that sin stocks are treated differently between countries depending on its culture and religion. The question that is answered in this study is: "What is the relationship between different cultural values of countries as measured by Hofstede and the excess return of sin stocks?" When regressing the excess returns against the dimensions of Hofstede, the dimensions masculinity versus femininity and indulgence versus restraint have negative coefficients that are significant at a $5 \%$ level. This implies that when nations are considered more masculine they are more likely to invest in sin stocks. On the contrary, their feminine counterparts are more likely to refrain from investing in sin stocks. When a country scores high on indulgence it is more likely to invest in sin stocks, whereas countries that score high on restraint are more likely to refrain from investing in sin stocks. The results are similar when using the threefactor model; consequently the interpretation of the results remains the same. When controlling for religion, only masculinity versus femininity remains significant.
\end{abstract}

\section{Introduction}

The Barrier Fund, better known as the Vice Fund, as it was previously called, is frequently seen as a collection of sin stocks. This fund invests in stocks in the tobacco, gambling, alcohol, and weapons/defense industry (USA Mutuals, 2014). As of October 2004, the Barrier Fund has continuously outperformed the S\&P500. An interest in sin stocks nowadays is almost ubiquitous, as newspapers from many continents publish articles about sin stocks being a good investment (Charles, 2014; Yeow, 2015; Zweig, 2015; Stevenson, 2015; Poljak; 2015). It seems as if investors have to choose between an unblemished conscience or an ample return on their investment; sin is in. According to Mackintosh and Authers (2015), there has been a medicinal, social and legal condemnation of alcohol and tobacco stocks for a century, yet remarkably their appeal remains.

The aim of this thesis is to investigate whether or not the cultural dimensions identified by Hofstede (1983) have an explanatory power on the excess returns of sin stocks. The results supplement to the existing literature by showing if country specific culture has an influence on sin stock performance. It investigates if culture can be seen as a further clarifying force for these excess sin stock returns. So far, most papers have focused on the analysis of sin stocks in just one country (Hong \& Kacperczyck, 2009), or have assumed that the outperformance of sin stocks is homogeneous across countries (Fabozzi, Ma \& Oliphant, 2008). Furthermore, the focus has often been on a particular geographic region, such as Europe (Salaber, 2007) or the Pacific-Basin (Durand, Koh \& Tan, 2012). Understanding the influence that

\footnotetext{
${ }^{1}$ Michelle Amory received a bachelor degree in International Business with a major in Finance at Maastricht University in 2015. At the moment she is working for Holland Corporate Finance as a Junior Associate until she starts with her Master's degree in August: Michelleamory@gmail.com

2 An extended version of the paper with appendices is available from the author.
}

\author{
Do different cultural \\ values affect the excess \\ return of sin stocks
}


culture has on equity valuations globally is nonetheless important because of the large size of these industries worldwide and the possibility that the level of the influence of culture is consequential.

The outline of the paper is as follows. Section two gives an overview of the existing literature on sin stocks followed by an overview of the existing literature on culture. Section three elaborates on the hypothesis development of this thesis. Section four focuses on the methodology, starting with information about the sin stock data and then continuing with information about the data on cultural dimensions. Section five shows the descriptive statistics. The main regressions and the empirical results of the study are presented in section six. Finally, a conclusion is given in section seven.

\section{Related literature}

This section first focuses on what sin stocks are. This question cannot be answered easily due to differences between countries and the application of the definition by authors, which differs substantially. Next, this section explains why sin stocks outperform the market. In addition, a possible explanation for this outperformance is provided by designing a new theoretical model, which is the transition to why culture is important when discussing sin stocks.

\subsection{Definition sin stocks}

Although there is not a distinct definition of sin stocks, there is some previous literature that tries to discern which stocks fall into this category. According to Reuteman (2014), sin stocks can include tobacco, weapons, gambling, and liquor and labels these stocks as the "four-legged stool". A more

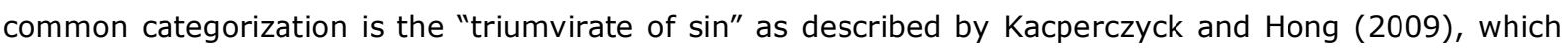
includes tobacco, alcohol, and gambling. Generally it is this definition that is used when researching on sin stocks. The sample of sin stocks of Kacperczyck and Hong however only includes firms with their primary listing in the US. The sample used in this study has 361 firms of which 106 are located in the US $(29 \%)$. It is therefore important to realize that this definition might not be suitable in this context. A broader definition is provided by the Oxford English Dictionary (2015): "A violation of some standard of taste or propriety". The defense industry is not included in the sample of Hong \& Kacperczyck because it is, according to these authors, not as similar as the other three industries. There are multiple aspects in which the defense industry differs from the tobacco, gambling and alcohol industry. First, the defense industry varies greatly per country, whereas the tobacco, smoking, and gambling industry are relatively similar. Second, some religions view alcohol, gambling, and tobacco as sinful however the defense industry is not considered a sin by most religions. Third, gambling, smoking, and consuming alcohol are all addictive and they are not easily substitutable. This does not apply to the defense industry. Fourth, the defense industry's taxes are not charged as a method to restrain consumption, unlike the alcohol, gambling, and tobacco industry (Salaber, 2007). There are however compelling reasons that argue for inclusion of the defense industry (Ahrens, 2004; Hamilton, 1993; Teoh, 1999). According to Social Investment Forum (2007), screening processes related to the defense and weapon industry are used by more than $56 \%$ of mutual funds. These mutual funds hold together an asset value of $\$ 38.8$ billion. When looking at all categories of funds, the defense industry accounts even for a larger part of the negative screening than the gambling industry does.

Furthermore, other preceding studies have included the defense industry (Fabozzi, Ma \& Oliphant, 2008; Durand, Koh \& Tan, 2012; Humphrey \& Tan, 2013; Waxler, 2004). Lastly, an additional reason to include the defense industry in the sample is because it is one of the four categories of the Barrier Fund. To 
account for the ambiguity regarding whether or not the defense industry can be seen as a sin, the analysis in this thesis is done twice. First the analysis is done with firms focused on the defense industry included.

\subsection{Sin stock returns}

According to empirical research of Hong \& Kacperczyk (2009) and Fabozzi, Ma \& Oliphant (2008), sin stocks have higher returns than other comparable stocks. This is confirmed by other studies, such as the study by Money Management (2006). An explanation for this phenomenon is the "neglected firm effect" that was first described by Arbel, Carvell \& Strebel (1983). The definition of a neglected firm is, according to Bhardwaj \& Brooks (1992), "[a firm that] is under less scrutiny by news agencies, financial analysts, and institutional investors than other firms". Investors are willing to pay a premium for a higher quality or quantity of information available about a particular stock. Given the fact that some institutions and individual investors shun sin stocks because of social norms, there is less information available due to the fact that there is less analyst coverage. As a result, there are fewer investors for sin stocks. Correspondingly, there exists a smaller investment base, implying reduced risk allocation and therefore investors require a higher return (Merton, 1987). The aversion of investors to investing in sin stocks causes the supply curve of capital to shift to the left, which changes the equilibrium compared to non-sin stocks. This is illustrated by line $S_{1}$ and line $S_{2}$ in figure 1 . When the supply curve shifts to the left, the cost of capital for a company is higher. Considering the cost of capital for companies is equal to the return for an investor, the return on sin stocks is higher compared to normal stocks. This can be seen by the new cost of capital and the old cost of capital.

Figure 1 Sin stock cost of capital and expected returns

Source: author.

(2000)

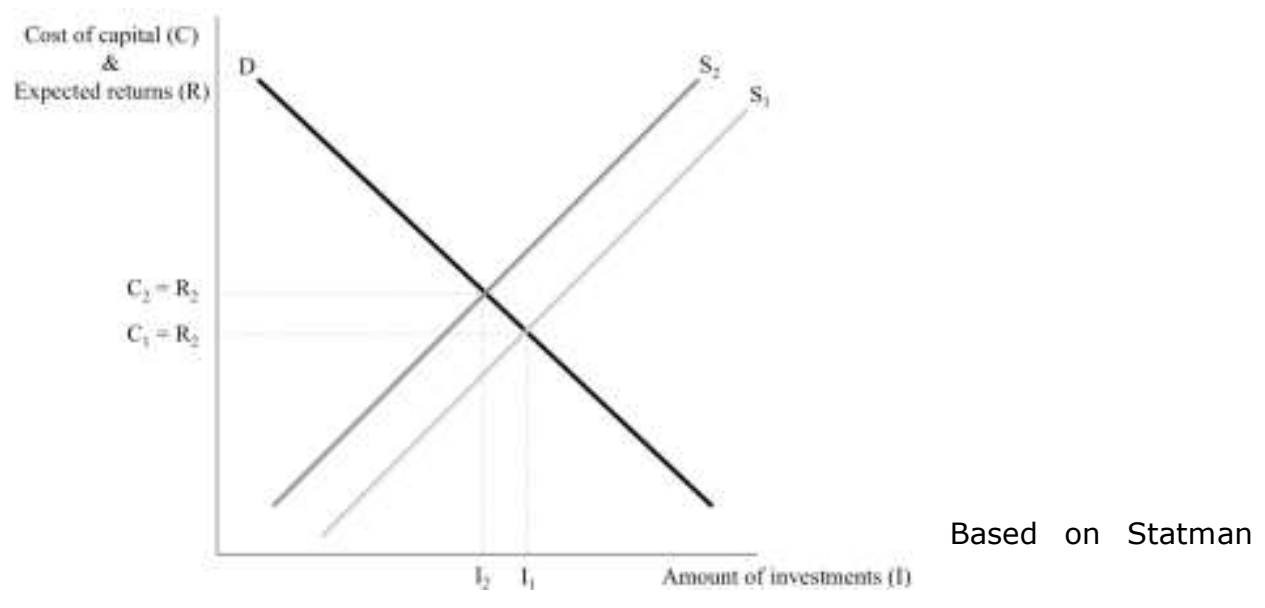




\subsection{Factors influencing financial decisions}

Finance can be affected by culture through three different channels according to Stulz \& Williamson (2003). They state that the first channel that can affect finance is values. A country's values depend on its culture. These values in turn could affect degree of aversion to investing in sin stocks. Research by Fauver \& McDonald (2013) has shown that in some countries, individuals, and institutions avoid investing in sin stocks, whereas in other countries investors do not shun these stocks. In countries where people view a firm as a sin firm, this firm's valuation goes down compared to the valuation of this firm in countries where it is not seen as a sin firm. In countries where people do not view certain firms as sin firms, the firms' valuations are not significantly different from non-sin firms. This shows that there is a significant relationship between social norms and equity valuations. The next channel through which culture can affect finance is institutions. An example of an institution that can be affected by culture is the legal system. This might influence sin stocks because investor protection, rules and regulations differ per country, which in turn might affect the aversion of investing in sin stocks. The last channel through which culture can affect finance is resource allocation. These differences in resources allocation in turn might affect the sin stocks' supply or demand. In this paper the focus will be on values, the first channel. The second channel, institutions, has been studied before by looking at for example litigation risk for sin stocks (Salaber, 2007; Hong \& Kacperczyk, 2011). The model of Stulz \& Williamson is depicted in figure 2a. However, there is evidence contrary to this model. Giannetti \& Yafeh (2012) argue that religion has an important role in shaping cultural values. More evidence contrary to the model of Stulz \& Williamson is provided by Schneider \& De Meyer (1991), who use religion as an explanation for cultural differences. Also, Ostwalt (2003) declares, "religion is necessarily entangled with secular culture". Clark \& Clanton (2012) write that "sacred and non-sacred elements of society are always interacting because the boundaries between the two are not firmly fixed", here, they refer to religion with sacred elements and refer to culture with non-sacred elements. There is much ambiguity around the relationship between religion and culture as can be concluded by the differences in the way articles apply the two. A respectable overarching description of the connection between religion and culture is given by Saroglou \& Cohen (2011) who state that there are six ways in which religion and culture might interact: "religion may be part of culture, constitute culture, include and transcend culture, be influenced by culture, shape culture, or interact with culture in influencing cognitions, emotions, and actions". In light of these findings, a new model is proposed. This model can be found in figure $2 b$.

Ownership of stocks can be influenced by three different elements: legal factors, political forces and cultural dimensions (De Jong \& Semenov, 2006). According to Salaber (2013), another factor that has a significant effect on shareholdings is religion. Salaber found that aggregated religious preferences in a country influence the valuation of these stocks. Stockholders in Protestant countries show a higher sin aversion than compared to their counterparts in Catholic countries.

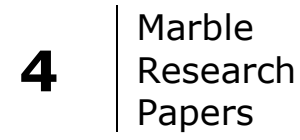


Figure 2a Model of Stulz \& Williamson.

According to this model, culture exists of values, institutions and resource allocations. These three factors influence finance.

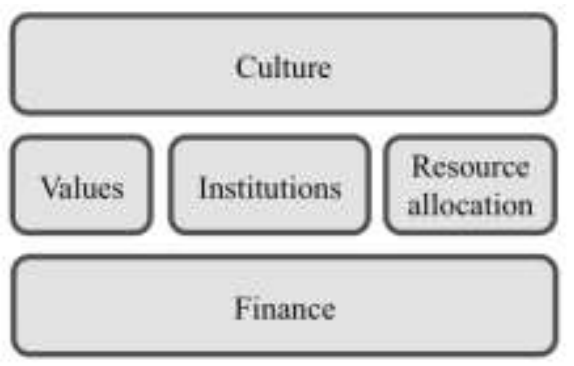

Figure $2 \mathrm{~b}$ Model of the author. Based on reasoning as mentioned in section 2.3. According to this model there is a relationship between culture and religion and this influences values, which in turn influences finance.

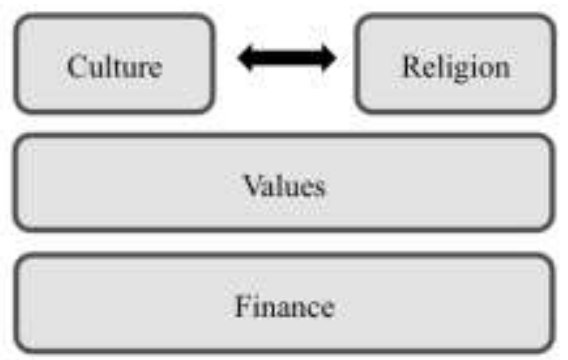

One of the reasons why Protestant countries might be more averse to sin stocks is because in Protestantism, gambling is seen as a sin (Ellison \& Nybroten, 1999), whereas Catholicism is open-minded about gambling (Diaz, 2000; Hoffman, 2000). Also, previous research indicates that Catholics have a more liberal view towards smoking and consuming alcohol compared to Protestants (Engs \& Mullen, 1999). Salaber (2007) finds that next to religion, legislation is another factor that has an influence on sin stock performance. In countries with higher litigation risk, sin stocks outperform the market because of higher external costs compared to countries where there is a lower risk of litigation. In addition, Salaber shows that in nations where the excise taxation ${ }^{3}$ is high, sin stocks earn significantly higher excess returns compared to countries where the excise taxation is lower, which indicates that sin stock returns differ with the level of excise taxation.

\subsection{Cultural dimensions}

Hofstede is one of the major management thinkers in the field of cross-cultural studies (Witzel \& Warner, 2013). The dimensions of Hofstede (n.d.) are used as a proxy for culture throughout this study. Using the dimensions of Hofstede as a proxy for culture is in line with several other articles. For example, Kwok \& Tadesse (2005) use the dimensions of Hofstede as a proxy for culture to test whether or not financial systems differ in their configuration because of culture. Furthermore, Licht, Goldschmidt \& Schwartz (2001), study the relations between investors' legal rights and national cultural profiles using the dimensions of Hofstede. Finally, Williams \& Zinkin (2008) test the effect of consumers' willingness to punish irresponsible corporate behavior. They show that that the propensity of consumers to punish firms for bad behavior varies in ways that appear to relate closely to the cultural characteristics identified by Hofstede. Hofstede (n.d.) provides an explanation of culture derived from social anthropology and defines it as: "the collective programming of the mind distinguishing the members of one group or category of people from another". The group or category in his research is defined as a nation. Culture can, according to the Oxford English Dictionary (2015), be defined as: "The ideas, customs, and social

\footnotetext{
3 "Excise taxation comprises all selective taxes and related levies and charges on tobacco, alcohol, gambling, pollution, driving, and other specific goods, services, and activities" (Salaber, 2007).
}

\section{Do different cultural values affect the excess return of sin stocks}


behavior of a particular people or society". For the purpose of this study, another suitable definition comes from Boyd \& Richerson (1985) who define culture as: "transmission from one generation to the next, via teaching and imitation, of knowledge, values, and other factors that influence behavior". Hofstede initially made a distinction between four different dimensions that define culture: the power distance index, individualism versus collectivism, masculinity versus femininity, and the uncertainty avoidance index. He later added two more dimensions: long term orientation versus short term normative orientation and indulgence versus restraint (Hofstede, Hofstede \& Minkov, 2010).

Hofstede (n.d.) mentions on his website that the Power Distance Index (PDI) can be defined as "the extent to which the less powerful members of institutions and organizations within a country expect and accept that power is distributed unequally". Each country has inequality, however how these different countries deal with inequality is different. Some cultures tolerate high inequality of power as well as wealth, whereas other countries have a lower tolerance for these inequalities (Hofstede, Hofstede \& Minkov, 2010). For countries that have a low tolerance for inequality, equal opportunities for all layers of society are stressed (Paul, 2011).

Countries are different in their degree of individualism. This causes some cultures to let the interest of the individual prevail over the interest of the group. These cultures are labeled individualistic. The view of people living in these individualistic countries is focused on "I" contrary to "we" or "us". The opposite of an individualistic society is a collectivist society in which the power of the group prevails over the individual. This type of society is focused on the "we" of the in-group and contradicts the "they" (Hofstede, Hofstede \& Minkov, 2010).

The third dimension that societies differ on refers to the distribution of emotional roles (Hofstede \& Hofstede, n.d.). According to Prosser \& Sitaram (1999) when a society scores high on femininity there is a presence of an emphasis on "relationships, diffidence, caring for the weak, and quality of life". To the contrary, countries that score high on masculinity focus on "achievement, heroism, assertiveness, and material success". In masculine societies people are not expected to take care of anyone but themselves and sometimes their immediate family members.

According to Hofstede (1983) uncertainty avoidance can be defined as "the degree to which the members of a society feel uncomfortable with uncertainty and ambiguity". Societies that dislike uncertainty will value structure and clear expectations. Contrary to uncertainty avoiding societies, countries that score low on the uncertainty avoidance index do not value rules and procedures and are willing to accept ambiguity (Mckee, Kemp \& Spence, 2013).

When a country has a long-term orientation, society is focused on future rewards in particular savings, persistence and adapting to changing circumstances. When a country's society is focused on the short term, it focuses on virtues related to the past and present. This includes national pride, respect for tradition, protection of appearance, and fulfilling social responsibilities (Deresky \& Christopher, 2012).

Countries that give in to the urges of individuals and allow a rather liberal fulfillment of basic human needs are labeled as indulgent countries. These countries have individuals who want to enjoy life and it is their goal to have fun. On the contrary, a country that scores high on restraint is a society that suppresses this fulfillment of basic human drives and makes sure its individuals do not give in to these urges by the establishment of strict social norms (Hofstede, n.d.).

\section{$6 \quad$ Marble




\section{Hypothesis development}

Hong \& Kacperczyk (2009) argue that excess sin stock returns are caused by the investor neglect effect arising from investors' discriminatory preferences against firms that engage in morally disputed undertakings. The discriminatory preferences that cause the excess returns may be existent because of culture. Culture has an influence on values, which in turn has an effect on finance decisions as can be seen in figure 2b. As a proxy for culture, the dimensions of Hofstede (1983) are used. The goal is to research whether there is a statistically significant relationship between the dimensions established by Hofstede and the observed abnormal returns of sin stocks of multiple countries worldwide. Understanding the influence that culture has on equity valuations is meaningful since the considerable volume of these industries globally and the chance that the degree of this influence on equity valuation is substantial. The overall research question of this paper is: "What is the relationship between different cultural values of countries and the excess sin stock returns?"

Since the score on the Power Distance Index contains information about the extent to which the less powerful members of institutions and organizations within a country expect and accept that power is distributed unequally, the expectation is that this has no influence refraining from sin stocks and therefore this dimension has no influence on the development of positive excess returns.

H1: Countries that score high on the Power Distance Index do not have significantly different excess returns from countries that score low on the Power Distance index.

It is probable that the degree of collectivism has an influence on the degree of investor aversion; the direction of this relationship is influenced by the groupthink, which is present in the collectivistic countries and is influenced by social norms, which are present in individualistic countries. Herding behavior influences both (Durand, Koh \& Tan, 2012). In collectivist countries it is important to comply with the social norms and values that are established by that society, contrary to individualistic countries, where the individuals care less about what the group thinks. Herding behavior is when an individual "would have made an investment without knowing other investors' decisions, but does not make that investment when she finds out that others have decided not to do so" (Bikhchandani \& Sharma, 2000). Individualistic cultures create a herding behavior away from investing in sin stocks because of social norms and therefore, cognitive dissonance is higher in these countries. For individuals in these countries, it is not a justification that many people in this particular country are holding sin stocks as well. In collectivist countries on the other hand, when many people in a country invest in sin stocks, individuals might feel as if it is justified for them to also hold these sin stocks; mental discord is reduced by others holding sin stocks. This can be explained by groupthink. Groupthink can be defined according to the Dictionary of Business and Management (2009) as: "In group decision making, the tendency to drift into ill-conceived policies or decisions without adequate debate. This can be a result of various pressures, including the illusion of in group superiority and the wish to achieve consensus and avoid painful disagreements." It seems plausible therefore, that in collectivistic countries individuals are less sin stock averse than individuals in individualistic countries are.

H2: Countries with a higher degree of individualism have higher excess sin stock returns compared to countries with a high degree of collectivism. 
According to Akerlof (1980) a social norm is an action whose utility to the agent executing it depends in a way on the beliefs or activities of other participants of the community. According to Durand, Koh \& Limkriangkrai (2012), this implies that at times the profit motive might be overridden by other motives. In line with this reasoning, the difference between countries in their degree of masculinity could cause a difference in preference for sin stocks. When people are more ego-oriented, they care less about the damage these sin stocks might have on other people or society as a whole and they care more about the profit motive. It therefore seems logical to assume that masculine countries experience fewer concerns when investing in sin stocks compared to countries that score high on femininity. Also, since achievement and material success is more important in masculine countries, it is more likely that they live by the saying: the end justifies the means. Masculine cultures focus on money, success, and competition, whereas in feminine countries quality of life and people are important. Because of these aforementioned reasons people in masculine countries probably show less resistance when investing in these sin stocks compared to people in feminine countries.

H3: Countries that are considered more masculine have lower excess sin stock returns compared to feminine countries.

According to Liston \& Soydemir (2010) a sin portfolio has an estimated beta of 0.5 , meaning it does not mimic the market and can therefore be used as a means of diversification thus making the portfolio less volatile. This study also makes a comparison between faith-based portfolios and sin portfolios. The results show that the Sharpe ratio is higher for sin portfolios when compared to faith-based portfolios, indicating the reward-to-risk is higher for sin portfolios. Additionally, sin stocks are more predictable according Kim \& Venkatachalam (2011), because as it turns out, sin firms have superior quality regarding financial reporting. This creates a better predictability of earnings for future cash flows, but also timely loss acknowledgment. Because of the aforementioned reasons, it seems plausible to assume that countries that score high on uncertainty avoidance are countries with individuals who are more likely to invest in sin stocks due to the fact that they want to avoid uncertainty and sin stocks offer this by having a lower beta, a higher Sharpe ratio and better predictability.

H4: Countries that score high on the uncertainty avoidance index have lower excess sin stock returns compared to countries that score low on the uncertainty avoidance index.

There seems to be no relationship between long term orientation versus short term normative orientation and the preference for sin stocks according to previous literature or logical reasoning.

H5: Countries that score high on short term normative orientation do not have significantly different excess returns from countries that score high on long term normative orientation.

Using logic reasoning, the expectation is that the degree of indulgence versus restraint has an effect on the aversion towards investing in sin stocks. In particular, countries that score high on indulgence are probably less averse towards investing in sin stocks. Contrarily, countries that score high on restraint are probably more averse towards investing in sin stocks.

H6: Countries with a high degree of indulgence lower excess sin stock returns compared to countries with a high degree of restraint.

\section{$8 \quad$\begin{tabular}{l|l} 
Marble \\
Research \\
Papers
\end{tabular}}




\section{Research methodology}

For the data analysis two types of data are needed. The first type of data needed is country data that shows how each country scores on all different dimensions. The other type of data is financial data. In the next section, sin stock data retrieval is discussed and in section following this one, Hofstede's cultural comparison is examined.

The Power Distance Index, individualism vs. collectivism, masculinity vs. femininity, uncertainty avoidance, short term vs. long term normative orientation and indulgence vs. restraint describe a country's culture according to Hofstede (1983).

\section{1 Portfolio selection and data cleaning}

In order to identify sin stocks, codes provided by the Industry Classification Benchmark are used. The ICB is, according to FTSE International Limited (2010), "a definitive system categorizing over 70,000 companies and 75,000 securities worldwide, enabling the comparison of companies across four levels of classification and national boundaries". As discussed above we need to identify sin stocks in the gambling, alcohol, defense and tobacco industry. The ICB works with categories on four levels, respectively: industry, supersector, sector and subsector. In order to identify these stocks Bloomberg is used and stocks in the following subsector categories are gathered: gambling (5752), brewers (3533), distillers \& vintners (3535), defense (2717), and tobacco (3785). The alcohol industry is a combination of brewers, distillers, and vintners. Bloomberg identifies a total of 625 stocks that fall under these particular ICB codes. Because the stocks are entered into Thomson Financial DataStream manually, it is important to check if there have been any mistakes; a static request was run in Thomson Financial DataStream to check for the ICB codes. The stocks that did not have the correct ICB code were deleted from the list. Some stocks could not be identified. In the end the total sample consists of 95 stocks in the defense industry, 51 stocks in the tobacco industry, 188 stocks in the gambling industry, 97 brewing companies, and 134 distillers \& vintners, which is a total of 560 sin stocks. These stocks are from 59 different countries from all over the world. These countries are identified using the tool geography group code provided by Datastream. All time series data is retrieved for the last 30 years.

\subsection{Empirical methods}

The first part of the analysis uses the Capital Asset Pricing Model (CAPM). To simplify, the CAPM is an investment theory predicting how much return you should receive to compensate for the amount of risk of your investment you are exposed to. The overall idea behind the CAPM is that shareholders need to be compensated in two ways: time value of money and risk. According to the CAPM formula, the necessary return on your investment exists of a risk-free part and a supplemental part, inherent in the risk of the company. The CAPM equation for the expected return is as follows:

$E\left[R_{i}\right]=r_{f}+\beta_{i} \times\left(E\left[R_{M k t}\right]-r_{f}\right)$

where $r_{i}$ is the expected return of security $i, r_{f}$ is the risk-free interest rate, $\beta_{i}$ is the beta of the security with respect to the market portfolio, and $E\left[R_{M k t}-r_{f}\right]$ is the risk premium for security i (Berk \& DeMarzo, 2011). This formula can be rewritten for the purpose of calculating the excess return of our sin stocks:

$R_{i, t}-R_{f, t}=\propto_{1}+\beta_{i} \times\left(R_{M k t, t}-r_{f, t}\right)+\varepsilon_{i, t}$ 
where $t$ stands for the month of observation. After calculating the excess return, the alpha of this regression can be used for the purpose of answering the problem statement by using equation 3 :

$\alpha_{1}=\alpha_{2}+\beta_{1} P D I+\beta_{2} I N D I V+\beta_{3} M A S+\beta_{4} U A I+\beta_{5} L T O+\beta_{6} I N D U L+\varepsilon_{t}$

where $\alpha_{1}$ stands for the excess return calculated using equation 2 per country, $\alpha_{2}$ accounts for all deviation not explained by the five cultural variables, PDI stands for the Power Distance Index, INDIV stands for individualism vs. collectivism, MAS stands for masculinity vs. femininity, UAI stands for the Uncertainty Avoidance Index, LTO stands for long vs. short term normative orientation and INDUL stands for indulgence vs. restraint. In order to be able to run this analysis the total return index $(R I)^{4}$ is required, which is a tool that shows values equal to the theoretical growth in value of a stock, with the assumption that dividends are reinvested. The closing bid price is used for the analysis. This tool is used for stocks of all industries. For the analysis, the risk-free rate of every country is necessary to calculate the excess market return. For the risk-free rate I derived the 10-year benchmark bond yield of each country with data from Thomson Reuters. Additionally, for the analysis the market return of each country is needed. The equity indices I used for the market return is the respective MSCI index for each country.

Although widely known, the CAPM has some major shortcomings, some due to the fact that it only uses a single factor to explain pricing and asset returns (Levy, 2012). As it turned out, the CAPM cannot explain the observed market returns very accurately, especially if firms drift far from the center. The deviations are mostly caused by small and value companies, which have consistently higher returns than the CAPM predicts (Armstrong, 2013). Therefore, the next part of the empirical analysis is the three-factor model of Fama \& French. Fama and French (1993) found statistically significant evidence that two types of stocks tended to have a higher excess return than the market as a whole, i.e. stocks with a low price-tobook ratio, also known as value stocks, and stocks with a relatively low market capitalization. In response to this, they added two factors to the CAPM formula to reflect these findings:

$R_{i, t}-R_{f, t}=\propto_{1}+\beta_{1} \times\left(E\left[R_{M k t, t}\right]-r_{f, t}\right)+\beta_{2} \times(S M B)+\beta_{3} \times(H M L)+\varepsilon_{i, t}$

where SMB stands for Small Minus Big and HML stands for High Minus Low. These are descriptions of respectively the market capitalization and book-to-market ratio. For this analysis all factors used in the analysis of the CAPM are needed. Furthermore, the market capitalization of each stock is needed, which is provided by Worldscope. The market capitalization ${ }^{5}$ is a representation of the total market value of a firm. The market price of year-end is calculated by the closing price of a company at the end of its fiscal year for non-US firms; for US firms it is equal to the closing price at the $31^{\text {st }}$ of December (worldscope). Additionally, we need the price to book value ${ }^{6}$ of each share, which can be taken from Datastream. Using these values it is possible to construct a "small minus big" (SMB) factor and a "high minus low" (HML) factor. This creates six portfolios with different sensitivities to the HML and SMB factors. In order to

\footnotetext{
${ }^{4} R I_{t}=R I_{t-1} * \frac{P I_{t}}{P I_{t-1}} *\left(1+\frac{D Y_{t}}{100} * \frac{1}{N}\right)$

where,

$R I_{t}=$ return index on day $t$

$R I_{t-1}=$ return index on previous day

$P I_{t}=$ price index on day $t$

$P I_{t-1}=$ price index on previous day

$D Y_{t}=$ dividend yield $\%$ on day $t$

$N=$ number of working days in the year (taken to be 260)

${ }^{5}$ Market price - year end $*$ common shares outstanding

${ }^{6} \frac{\text { Share price }}{\text { Book value per share }}$

$10 \mid \begin{aligned} & \text { Marble } \\ & \text { Research } \\ & \text { Papers }\end{aligned}$
} 
create these portfolios, stocks are first sorted with respect to price-to-book value. Three portfolios are formed, i.e. a portfolio that includes companies with a low price-to-book ratio, a portfolio with companies that have a medium price-to-book ratio, and a portfolio with companies that have a high price-to-book ratio. Successively, these three portfolios are again divided into two portfolios each, this time using market capitalization information to split between small and big market capitalizations. The formula for the SMB factor is:

$S M B=\frac{1}{3}(H S+M S+L S)-\frac{1}{3}(H B+M B+L B)$

where HS stands for high price-to-book ratio and a small market capitalization, MS stands for medium price-to-book ratio and a small market capitalization, LS stands for low price-to-book ratio and a small market capitalization, HB stands for high price-to-book ratio and a big market capitalization, MB stands for medium price-to-book ratio and a big market capitalization, and finally LB stands for low price-tobook ratio and a big market capitalization.

The formula for the HML factor is:

$H M L=\frac{1}{2}(H B+H S)-\frac{1}{2}(L B-L S)$

The conclusion that can be derived about the factors when looking at the formulas is that HML takes the spread in returns between value and growth stocks into consideration, whereas SMB accounts for the spread in returns between small- and large-sized firms.

After calculating the excess return, the alpha of this regression can be used for the purpose of answering the problem statement by using equation 3, only then with the alphas derived from equation 4 instead of equation 2 .

\subsection{Cultural country data}

The cultural country data were retrieved from the website of Hofstede (n.d.) using the cultural tool called 'country comparison'.

\subsection{Data transformation}

After deleting Israel from the sample, the final sample is ready for data transformation. In order to perform any statistical analysis, I transformed the panel data and made sure all observations are listed according to firm code and time of observation. After this data transformation, I calculated the percentage return of each observation, $\mathrm{r}_{\mathrm{i}}{ }^{7}$, and following I calculated the excess return by subtracting the risk-free rate from the $r_{i}$. The risk-free rate was annualized so I transformed this into monthly data ${ }^{8}$. The market return of each country was transformed into the percentage return in the same way as the $r_{i}$ has been calculated, which provides us $\mathrm{rm}$. The excess market return is calculated by subtracting the risk-free rate from the $r_{m}$. In order to be able to do a regression I deleted every row that had a missing value. The calculation of the data can be heavily influenced by extreme values.

\footnotetext{
${ }^{7} r_{i}=\frac{R I_{t}-R I_{t-1}}{R I_{t-1}}$

${ }^{8}$ Monthly rate $=(1+\text { annual rate })^{\left(\frac{1}{12}\right)}-1$
} 


\subsection{Indicator variables for religion}

As shown by the model depicted in figure $2 b$, religion has an influence on culture. An outing of this influence might be that there are discrepancies between countries on whether they view certain industries as sinful or not due to the prevalence of certain religions, as has been shown by Salaber (2007) and Salaber (2013). To account for this difference and in order to clearly identify the relationship between culture and excess sin stock returns, it is important to include religion in the regression as a control variable.

\section{Descriptive statistics}

In table 1 , the number of sin firms per country is shown. There are 21 countries in total. The US provides most of the sin firms in the sample; Bulgaria, Indonesia, the Russian Federation and Singapore provide the minimum of five sin firms per country. Table 1 also provides information on how many number of firms are included in the sample per sin industry. There are 64 firms in the defense industry, 49 brewers, 80 distillers \& vintners, 31 tobacco firms and 137 firms in the gambling industry. There are 361 firms in total.

Table 1 Number of sin firms per country and number of firms per industry.

\begin{tabular}{|llll|}
\hline Number of sin firms per country & \multicolumn{3}{l|}{ Number of sin firms per industry } \\
\hline Australia & 18 & 2717 & 64 \\
\hline Bulgaria & 5 & 3533 & 49 \\
\hline Canada & 15 & 3535 & 30 \\
\hline Chile & 6 & 3785 & 137 \\
\hline China & 31 & 5752 & \\
\hline France & 19 & & \\
\hline Germany & 15 & \\
\hline Greece & 7 & \\
\hline Hong Kong & 24 & \\
\hline India & 6 & \\
\hline Indonesia & 5 & \\
\hline Japan & 19 & \\
\hline Malaysia & 9 & \\
\hline Philippines & 12 \\
\hline Russian Federation & 5 \\
\hline Singapore & 5 & \\
\hline South Africa & 6 & \\
\hline South Korea & 10 \\
\hline Sweden & 6 \\
\hline United Kingdom & 32 \\
\hline United States & 106 \\
\hline The & & \\
\hline
\end{tabular}

The time-period is from 1985 until 2015.

In table 2, the descriptive statistics for all variables are reported. Included in the table are the number of observations per variable, the mean, the three quartiles, and the standard deviation. The standard deviation of the sin stock portfolio is larger than the market portfolio, which makes sense because the market portfolio includes more stocks and is therefore more diversified. In the research of Fabozzi, Ma \& Oliphant (2008), the average excess sin stock return was 0,95\%, compared to 0,7\% found in table 2 taken from this sample. In the research of Hong \& Kacperczyk (2009) the average excess sin stock return was $0,96 \%$. This discrepancy could be explained because of the time-period chosen, the countries

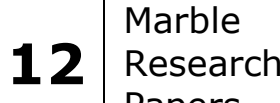

Papers 
chosen and the industries included in the sample. Fabozzi, Ma \& Oliphant use time-series data of the period 1970-2007 and include adult services, alcohol, biotech, defense, gaming and tobacco as sin stocks. Their sample includes Australia, Belgium, Canada, Denmark, Finland, France, Germany, Hong Kong, Italy, Japan, Korea, the Netherlands, Norway, Portugal, Singapore, Spain, Sweden, Switzerland, Taiwan, United Kingdom, and the United States. Hong \& Kacperczyk used a period of 1980-2006 and included the triumvirate of sin. Additionally, they focus only on the United States. Durand, Koh \& Tan (2012) find the opposite of the previously mentioned two articles, and reports to have found that investors in the Asia-Pacific, specifically Australia, India, Japan, South Korea, Malaysia, New Zealand and Singapore, pay more for sin stocks than for other firms, implying their sin stock average excess return lies below the average excess market return. The time-period chosen in this article ranges from 1990 until 2009 and includes the alcohol, tobacco, gaming and defense industry. Considering all but one of the countries included in the article of Durand, Koh \& Tan are also included in the sample used in this paper, a probable reason for an excess sin stock return lower than that measured by Hong \& Kacperczyk and Fabozzi, Ma \& Oliphant can be explained by the differences between the countries included in the sample.

Table 2 Descriptive statistics

\begin{tabular}{|lllllllll|}
\hline & Obs. & Mean & Min & $\mathbf{2 5} \%$ & Median & $\mathbf{7 5 \%}$ & Max & SD \\
\hline TR & 53590 & 5233,1 & 0,0 & 9,7 & 80,0 & 386,8 & 1242540,3 & 48541,5 \\
\hline Ri & 53590 & 0,010 & $-0,676$ & $-0,057$ & 0,000 & 0,064 & 1,300 & 0,131 \\
\hline Ri - Rf & 53590 & 0,007 & $-0,683$ & $-0,061$ & $-0,003$ & 0,061 & 1,293 & 0,131 \\
\hline MC & 53590 & 2499602 & 342,0 & 35019 & 182473 & 1075748 & 152572726 & 8759609 \\
\hline PTB & 53590 & 2,863 & $-30,770$ & 1,040 & 1,860 & 3,380 & 45,160 & 4,812 \\
\hline Rf year & 53590 & 4,648 & 0,341 & 3,147 & 4,234 & 5,570 & 37,163 & 2,590 \\
\hline Rf month & 53590 & 0,004 & 0,000 & 0,003 & 0,003 & 0,005 & 0,027 & 0,002 \\
\hline TRM & 53590 & 2782,9 & 0,1 & 50,9 & 2417,2 & 3850,5 & 15770,4 & 3022,4 \\
\hline Rm & 53590 & 0,008 & $-0,473$ & $-0,024$ & 0,012 & 0,047 & 0,432 & 0,065 \\
\hline Rm - Rf & 53590 & 0,005 & $-0,480$ & $-0,028$ & 0,009 & 0,043 & 0,425 & 0,066 \\
\hline
\end{tabular}

As can be seen from table 3, the average excess return is highest for the tobacco industry, with an average excess return of $1,090 \%$. The mean excess return is lowest for brewers, with an average excess return of $0,491 \%$. Table 3 shows that there are large differences between countries and the average excess return sin stocks have. What is striking, is that Greece has an average negative excess return, which means that the risk-free rate in this country provides more return than sin stocks do. An explanation for this observation could be that Greece has a very high "risk-free" rate.

Do different cultural values affect the excess return of sin stocks 
Table 3 The average excess return of sin stocks for each country and per industry.

\begin{tabular}{|llll|}
\hline Country & Average & Industry & Average excess return \\
\hline 1. Indonesia & $1,75 \%$ & 3785 & $1,09 \%$ \\
\hline 2. Sweden & $1,72 \%$ & 2717 & $0,70 \%$ \\
\hline 3. India & $1,29 \%$ & 3535 & $0,64 \%$ \\
\hline 4. Bulgaria & $1,24 \%$ & 5752 & $0,62 \%$ \\
\hline 5. China & $1,18 \%$ & 3533 & $0,49 \%$ \\
\hline 6. South Korea & $1,04 \%$ & & \\
\hline 7. Hong Kong & $0,88 \%$ & \\
\hline 8. Russia & $0,86 \%$ & \\
\hline 9. US & $0,75 \%$ & \\
\hline 10. Japan & $0,75 \%$ & \\
\hline 11. Australia & $0,57 \%$ & \\
\hline 12. South Africa & $0,55 \%$ & \\
\hline 13. France & $0,55 \%$ & \\
\hline 14. UK & $0,35 \%$ & \\
\hline 15. Malaysia & $0,34 \%$ & \\
\hline 16. Canada & $0,32 \%$ & \\
\hline 17. Singapore & $0,32 \%$ & \\
\hline 18. Chile & $0,27 \%$ & \\
\hline 19. Philippines & $0,25 \%$ & \\
\hline 20. Germany & $0,02 \%$ & \\
\hline 21. Greece & $-0,05 \%$ & \\
\hline The & & \\
\hline
\end{tabular}

The time-period of the sample is from 1985 until 2014. The table is numerically ordered. In countries 1 until 13 , the average excess return of sin stocks is higher than the excess market return $(0,46 \%)$. In countries 14 until 21, the sin stock average excess return is below the excess market return. Each industry has an excess sin stock return above the excess market return.

In line with equation 4, the HML and SMB factors have to be calculated in order to be able to use the three-factor model. In table 4 the average values for each of the six portfolios are reported. The average values of SMB and HLM per year are calculated by creating portfolios as described in the research methodology section.

Table 4 Six different portfolios resulting from the construction of the SMB and HML factors.

\begin{tabular}{|c|c|c|c|}
\hline & Low & Medium & High \\
\hline Small & $-0,698$ & $-0,408$ & $-0,0213$ \\
\hline Big & 0,497 & 0,316 & 0,177 \\
\hline
\end{tabular}

The average returns of each of these portfolios are shown below. The time-period used is 1985-2014.

In line with the reasoning provided in the research methodology section, it is important to include religion as a control variable in the regression. In order to do this, dummy variables have been created, categorizing countries using their major religion, following the reasoning of Stulz \& Williamson (2003). The major religions have been derived from E. Murray (2011). Table 5 shows the shows the distribution of each religion per country.

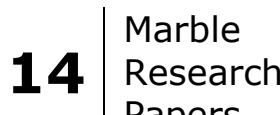

Papers 
Table 5 Coding of the dummy variables for religion per country.

\begin{tabular}{|c|c|c|c|c|c|c|c|c|}
\hline \multirow[t]{2}{*}{ Country } & \multicolumn{8}{|c|}{ Religion } \\
\hline & Catho-lic & $\begin{array}{l}\text { Protes- } \\
\text { tant }\end{array}$ & Orthodox & Islam & Buddhist & $\begin{array}{l}\text { Chinese folk } \\
\text { religions }\end{array}$ & Hindu & Shinto \\
\hline Australia & 1 & 0 & 0 & 0 & 0 & 0 & 0 & 0 \\
\hline Bulgaria & 0 & 0 & 1 & 0 & 0 & 0 & 0 & 0 \\
\hline Canada & 1 & 0 & 0 & 0 & 0 & 0 & 0 & 0 \\
\hline Chile & 1 & 0 & 0 & 0 & 0 & 0 & 0 & 0 \\
\hline China & 0 & 0 & 0 & 0 & 0 & 1 & 0 & 0 \\
\hline France & 1 & 0 & 0 & 0 & 0 & 0 & 0 & 0 \\
\hline Germany & 0 & 1 & 0 & 0 & 0 & 0 & 0 & 0 \\
\hline Greece & 0 & 0 & 1 & 0 & 0 & 0 & 0 & 0 \\
\hline Hong Kong & 0 & 0 & 0 & 0 & 0 & 1 & 0 & 0 \\
\hline India & 0 & 0 & 0 & 0 & 0 & 0 & 1 & 0 \\
\hline Indonesia & 0 & 0 & 0 & 1 & 0 & 0 & 0 & 0 \\
\hline Japan & 0 & 0 & 0 & 0 & 0 & 0 & 0 & 1 \\
\hline Malaysia & 0 & 0 & 0 & 1 & 0 & 0 & 0 & 0 \\
\hline Philippines & 1 & 0 & 0 & 0 & 0 & 0 & 0 & 0 \\
\hline Russia & 0 & 0 & 1 & 0 & 0 & 0 & 0 & 0 \\
\hline Singapore & 0 & 0 & 0 & 0 & 1 & 0 & 0 & 0 \\
\hline South Africa & 0 & 1 & 0 & 0 & 0 & 0 & 0 & 0 \\
\hline South Korea & 1 & 0 & 0 & 0 & 0 & 0 & 0 & 0 \\
\hline Sweden & 0 & 1 & 0 & 0 & 0 & 0 & 0 & 0 \\
\hline UK & 0 & 1 & 0 & 0 & 0 & 0 & 0 & 0 \\
\hline US & 1 & 0 & 0 & 0 & 0 & 0 & 0 & 0 \\
\hline
\end{tabular}

\section{Empirical results}

\subsection{One-factor model}

The first part of the analysis uses the CAPM, as described in the research methodology, to attempt to answer the problem statement. In order to get a general overview, table 6 regresses the excess market return against the excess sin stock return.

Table 6 The estimation results of equation 2.

\begin{tabular}{|c|c|c|c|c|c|}
\hline \multirow[b]{2}{*}{ Model } & \multicolumn{2}{|c|}{ Unstandardized Coefficients } & \multicolumn{3}{|c|}{ Standardized Coefficients } \\
\hline & B & Std. Error & Beta & $\mathrm{t}$ & Sig. \\
\hline 1 ALPHA_1 & ,005 & ,001 & & 9,536 & , 000 \\
\hline Rm_min_Rf & ,261 & ,009 & 131 & 30,609 & ,000 \\
\hline
\end{tabular}

Dependent Variable: Ri_min_Rf.

Rm_min_Rf stands for the excess market return and Ri_min_Rf stands for the excess sin stock return. The time period used ranges from 1985 until 2014. There are 21 countries included in this analysis. The risk-free rate used is the 10-year bond yield corresponding to each country. For the market return the respective MSCI per country are used. The data is on a monthly basis.

What can be seen from table 5 is that sin stocks in general of the 21 countries included outperform the market by $0.5 \%$. Furthermore, the beta of sin stocks compared to the market is 0.261 , which implies

Do different cultural values affect the excess return of sin stocks 
that the sin stocks are less volatile than the market portfolio is. Having a beta below one classifies it as a defensive asset $^{9}$ (Khan \& Jain, 2008). The next step is to run the same regression as in table 5 , only then for each country separately.

The independent variables are the excess sin stock returns. The time period used ranges from 1985 until 2014. There are 21 countries included in the analysis. The risk-free rate used is the 10 -year bond yield corresponding to each country. For the market return the respective MSCI per country are used. The data is on a monthly basis.

In 12 out of 21 countries, a significant alpha is found. No country has a negative alpha, which means that sin stocks have outperformed the market. A noticeable feature is that most countries in the top half of table 7 are Asian (Indonesia, China, India, Russia, South Korea, Japan, Hong Kong), whereas most countries in the bottom half are considered Western cultures (US, France, South Africa, Australia, Greece, UK, Canada, Germany, Chile). However, considering the differences in $R^{2}$, caution is necessary when deriving conclusions from this data. Chile has the highest $R^{2}$, which is 0.097 and China has an $R^{2}$ of 0.001 , which is the lowest observed $R^{2}$ value.

Table 7 The estimation results of equation 2 per country.

\begin{tabular}{|c|c|c|c|c|c|}
\hline \multirow[t]{2}{*}{ County } & \multicolumn{2}{|l|}{ Alpha } & \multicolumn{2}{|c|}{ Excess Market Return } & \multirow{2}{*}{$\begin{array}{l}\text { Statistics } \\
\text { Adjusted } \mathrm{R}^{2}\end{array}$} \\
\hline & $\propto_{1}$ & P-value & $\beta_{i}$ & P-value & \\
\hline Sweden & $0.016^{* * *}$ & 0.001 & $0.219^{* * *}$ & 0.000 & 0.017 \\
\hline Indonesia & $0.016^{* * *}$ & 0.002 & $0.097^{*}$ & 0.071 & 0.004 \\
\hline Bulgaria & $0.015^{* *}$ & 0.045 & $0.170^{* *}$ & 0.013 & 0.015 \\
\hline China & $0.012^{* * *}$ & 0.000 & $-0.052^{*}$ & 0.061 & 0.001 \\
\hline India & 0.012 & 0.200 & $0.382^{* * *}$ & 0.000 & 0.020 \\
\hline Russia & 0.010 & 0.199 & $0.179^{* *}$ & 0.014 & 0.019 \\
\hline South Korea & $0.009^{* * *}$ & 0.006 & $0.210^{* * *}$ & 0.000 & 0.018 \\
\hline Japan & $0.007^{* * *}$ & 0.000 & $0.547^{* * *}$ & 0.000 & 0.086 \\
\hline Hong Kong & $0.007^{* *}$ & 0.030 & $0.352^{* * *}$ & 0.000 & 0.020 \\
\hline US & $0.006^{* * *}$ & 0.001 & $0.307^{* * *}$ & 0.000 & 0.015 \\
\hline France & $0.005^{* * *}$ & 0.002 & $0.112^{* * *}$ & 0.000 & 0.004 \\
\hline South Africa & 0.005 & 0.376 & $0.382^{* * *}$ & 0.000 & 0.038 \\
\hline Australia & $0.004^{* * *}$ & 0.003 & $0.401^{* * *}$ & 0.000 & 0.029 \\
\hline Greece & $0.003^{* * *}$ & 0.004 & $0.360^{* * *}$ & 0.000 & 0.058 \\
\hline UK & $0.002^{*}$ & 0.092 & $0.370^{* * *}$ & 0.000 & 0.034 \\
\hline Philippines & 0.002 & 0.625 & $0.169^{* * *}$ & 0.000 & 0.010 \\
\hline Chile & 0.002 & 0.454 & $0.362^{* * *}$ & 0.000 & 0.097 \\
\hline Canada & 0.001 & 0.597 & $0.310^{* * *}$ & 0.000 & 0.025 \\
\hline Malaysia & 0.001 & 0.789 & $0.453^{* * *}$ & 0.000 & 0.048 \\
\hline Singapore & 0.001 & 0.923 & $0.350^{* * *}$ & 0.000 & 0.024 \\
\hline Germany & 0.000 & 0.804 & $0.119^{* * *}$ & 0.000 & 0.007 \\
\hline
\end{tabular}

* Correlation is significant at the 0.010 level (2-tailed).

$* *$ Correlation is significant at the 0.005 level (2-tailed).

$* * *$ Correlation is significant at the 0.01 level (2-tailed).

${ }^{9}$ Defensive stocks remain stable during the numerous stages of the economic cycle. During downturns they tend to perform superior to the market; during a growth stage it has returns below that of the market.

16 Research

Papers 
The correlation between dependent and independent variables influences the capability of an independent variable to forecast the dependent variable. When adding more than one independent variable, which is the case here considering there are six variables, attention has to be paid to the intercorrelation between the independent variables. When there is intercorrelation found between these six variables, the correlation among the independent variables should only be counted once in the regression analysis, because when the second intercorrelated independent variable would be added to the analysis, the relationship would appear to be weaker than it actually is, due to the fact that in the regression analysis only the variance that it shares with the dependent variable is integrated into the analysis (Sharpe, De Veaux \& Velleman, 2011).

Significant intercorrelations at the $1 \%$ level can be found between individualism vs. collectivism and the Power Distance Index, indulgence vs. restraint and the Power Distance Index, indulgence vs. restraint and individualism vs. collectivism, indulgence vs. restraint and long term vs. short term normative orientation. Significant intercorrelations at the $10 \%$ level can be found between indulgence vs. restraint and ALPHA_2 and between individualism vs. collectivism and short term vs. long term normative orientation. Considering the hypotheses stated it is important to take the correlation between INDUL and INDIV and between LTO and INDIV into consideration. The other correlations are trivial, bearing in mind that PDI and LTO are hypothesized to have no effect and therefore are not included in the next part of the analysis. The independent variables are alphas of the excess sin stock returns as calculated in table 6. The time period used ranges from 1985 until 2014. There are 21 countries included in the analysis. The cultural values are derived from the website of Hofstede (n.d.) and ranges between 0 and 100.

In model (1) all dimensions of Hofstede have been included. In model (2) only the dimensions of Hofstede have been included that according to the hypotheses development section. In model (3) is the same as model (2), except INDIV is not included in the analysis because of the results of table 8.

Table 8 Correlations between ALPHA_2 and the dimensions of Hofstede

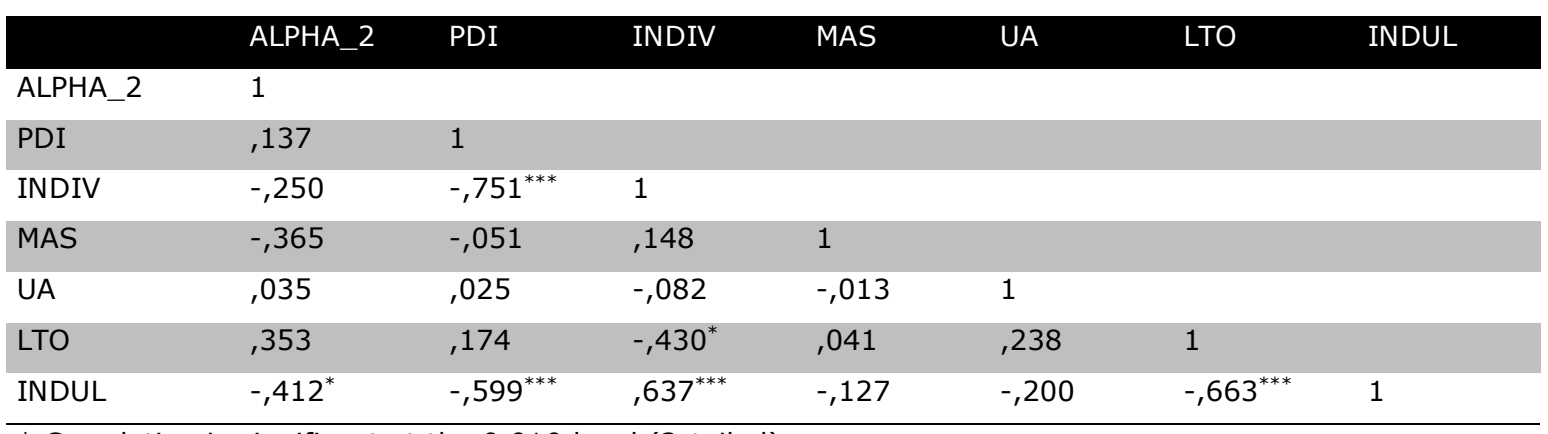

* Correlation is significant at the 0.010 level (2-tailed).

** Correlation is significant at the 0.005 level (2-tailed).

$* * *$ Correlation is significant at the 0.01 level (2-tailed).

As can be seen from table 9, when all dimensions are included, none of them are significant. This might be because of intercorrelation between the dimensions as shown by table 8 . The signs are the same all both models; there is a negative relationship between ALPHA_2 and PDI, ALPHA_2 and MAS, ALPHA_2

Do different cultural values affect the excess return of sin stocks 
and UA and ALPHA_2 and INDUL. There is a positive relationship between ALPHA_2 and INDIV, and ALPHA_2 and LTO.

Table 9 The estimation results of equation 3 per country.

\begin{tabular}{|llll|}
\hline Variables & $(\mathbf{1})$ All & (2) Hypothesized & (3) Without INDIV \\
\hline ALPHA_2 & 2.518 & $2.034 * * *$ & 1.967 \\
& $(0.102)$ & $(0.001)$ & $(0.001)$ \\
\hline PDI & -0.006 & & \\
\hline INDIV & $(0.548)$ & 0.004 & \\
\hline MAS & 0.001 & $(0.449)$ & $-0.012^{* *}$ \\
& $(0.853)$ & $-0.014^{* *}$ & $(0.045)$ \\
\hline UA & -0.014 & $(0.037)$ & -0.001 \\
& $(0.050)$ & -0.002 & $(0.745)$ \\
\hline LTO & -0.002 & $(0.707)$ & \\
\hline INDUL & $(0.658)$ & & $-0.013^{* *}$ \\
& 0.001 & $0.029)$ \\
\hline
\end{tabular}

Dependent variable: ALPHA_2

* Correlation is significant at the 0.010 level (2-tailed).

$* *$ Correlation is significant at the 0.005 level (2-tailed).

$* * *$ Correlation is significant at the 0.01 level (2-tailed).

Model 2 of table 9 shows a significant relationship between MAS and ALPHA_2 and INDUL and ALPHA_2, which is in line with hypothesis 3 and hypothesis 6. Also, PDI and LTO are not significant as predicted by hypothesis 1 and 5. There is no support for hypotheses 2 and 4. In model (3) INDIV is not included because this is the variable that was insignificant in model (2), but has a high significant correlation with INDUL and with LTO. The conclusions do not change compared to model (2). Table 8 implies that countries with a high degree of masculinity, such as Japan and the Philippines have lower excess returns relative to countries with a high degree of femininity, such as Sweden and Bulgaria. Additionally, table 8 implies that countries that are considered to score high on indulgence, such as the United Kingdom and the United States have a lower excess return compared to countries that score high on restraint, such as Hong Kong and Russia.

\subsection{Three-factor model}

The second part of the analysis is the three-factor model. The same steps as in the previous section are followed. Table 10 summarizes the estimation results of the three-factor model.

Table 10 The estimation results of equation 4.

\begin{tabular}{|c|c|c|c|c|c|}
\hline Model & \multicolumn{2}{|c|}{ Unstandardized Coefficients } & \multicolumn{3}{|l|}{ Standardized Coefficients } \\
\hline 1 ALPHA_1 & ,005 & ,001 & & 8,597 &, 000 \\
\hline Rm_Min_Rf & ,255 & ,009 & 128 & 29,854 &, 000 \\
\hline SMB &,- 062 & ,007 &,- 067 & $-8,512$ & ,000 \\
\hline HML & ,080 & ,008 & ,081 & 10,277 & ,000 \\
\hline
\end{tabular}

Dependent Variable: Ri_Min_Rf 
Rm_min_Rf stands for the excess market return and Ri_min_Rf stands for the excess sin stock return. The time period used ranges from 1985 until 2014. There are 21 countries included in this analysis. The risk-free rate used is the 10-year bond yield corresponding to each country. For the market return the respective MSCI per country are used. SMB and HML are calculated according to equation 5 and 6 .

The adjusted $\mathrm{R}^{2}$ improved from 0.017 to 0.019 , ALPHA_1 stayed the same and the beta of the excess market return decreased by 0.006 . Both SMB and HML are significant at a $1 \%$ level. The SMB factor is negative, implying that sin stocks are mostly large capitalization funds as can be concluded from the formula, whereas HML is positive, suggesting sin stocks included in the simple are value stocks, meaning they have a high value premium compared to other stocks, which is consistent with the relative low price-to-book ratio for sin stocks. These results are consistent with Salaber (2007) and Durand, Koh \& Limkriangkrai (2012), who also found a beta lower than 1, a positive HML factor, a negative SMB factor, and in absolute terms a higher HML than SMB factor. Next, the same analysis is done for each country individually. The top 5 using the CAPM consists of Sweden, Indonesia, Bulgaria, China and India. Using the three-factor model it still exists of these countries, although in a different order. A noticeable difference is that there are now more countries that seem to have sin stock excess returns that do not outperform the market, i.e. Singapore, Malaysia, and Germany, although none of them are significant.

Next, we regress the excess sin stock returns (ALPHA_2) against the cultural variables. The time period used ranges from 1985 until 2014. There are 21 countries included in the analysis. The cultural values are taken from the website of Hofstede (n.d.) and ranges between 0 and 100 . In model (1) all dimensions of Hofstede have been included. In model (2) only the dimensions of Hofstede have been included that according to the hypotheses development section.

As can be seen from table 11, when all dimensions are included, only MAS is significant, considering MAS has no correlation with either one of the other dimensions.

Table 11 The estimation results of equation 3 per country, using equation 4 to calculate the alphas.

\begin{tabular}{|llll|}
\hline Variables & $(\mathbf{1})$ All & (2) Hypothesized & (3)Without INDIV \\
\hline ALPHA_2 & 2.017 & $1.9 * * *$ & $1.871^{* * *}$ \\
& $(0.239)$ & $(0.006)$ & $(0.004)$ \\
\hline PDI & -0.004 & & \\
\hline INDIV & $(0.700)$ & 0.002 & $-0.013^{*}$ \\
& 0.000 & $(0.771)$ & $(0.062)$ \\
\hline MAS & $(0.980)$ & $-0.014 *$ & -0.001 \\
& $-0.013^{*}$ & $(0.070)$ & $(0.894)$ \\
\hline UA & $(0.090)$ & -0.001 & \\
\hline LTO & -0.001 & $(0.880)$ & $-0.012 *$ \\
& $(0.802)$ & & $(0.061)$ \\
\hline INDUL & 0.003 & -0.014 & \\
& $(0.698)$ & $(0.119)$ & \\
\hline
\end{tabular}

Dependent variable: ALPHA 2

* Correlation is significant at the 0.010 level (2-tailed).

** Correlation is significant at the 0.005 level (2-tailed).

$* * *$ Correlation is significant at the 0.01 level (2-tailed).

Do different cultural values affect the excess return of sin stocks 
The signs are the same for all three models; there is a negative relationship between ALPHA_2 and PDI, ALPHA_2 and MAS, ALPHA_2 and UA and ALPHA_2 and INDUL. There is a positive relationship between ALPHA_2 and LTO. The only difference now is that INDIV seems to have no effect on ALPHA_2. Model (2) of table 10 shows a significant relationship between MAS and ALPHA_2, which is in line with hypothesis 3. Also, PDI and LTO are not significant as predicted by hypothesis 1 and 5 . There is no support for hypotheses 2, 4 and 6. In model (3) INDIV is not included because this is the variable that was insignificant in model (2), but has a very high correlation with INDUL. Now INDUL is significant at a $10 \%$ level, which offers support for hypothesis 6 . The reason why individualism vs. collectivism does not have an influence on the excess return of sin stocks might be explained because of the behavior of herding and groupthink. Societies that are collectivistic, herd towards what others do. Societies that are individualistic, herd towards societal norms. When the sample includes countries that have societal norms that result in the same behavior as what the majority of people invest in in collectivistic countries, then this results in the same behavior in both collectivistic and individualistic countries. A way to solve this problem could be to add a conditional hypothesis and include an interaction variable that allows exploring the synergistic effects of combined independent variables, but this goes beyond the scope of this thesis.

\subsection{Controlling for religion}

The regressions up to so far have not yet taken religion into account. As explained in the research methodology section, it is important to include this as a control variable to ensure that we can clearly identify the relationship between culture and the abnormal return of sin stocks. Table 12 gives an overview of the correlations. In model (1) all dimensions of Hofstede have been included. In model (2) only the dimensions of Hofstede have been included that according to the hypotheses development section.

Catholicism is used as a baseline for this regression. The indicator variable of Shinto is significant in the third model, which means that the intercept differences are large enough to justify the addition of the religion variables. In this model the dimension of indulgence versus restraint is no longer significant. Masculinity versus femininity remains significant with a coefficient of -0.022 , meaning that a one-point increase in masculinity decreases excess sin stock returns by 0.022 per month. This is because countries that rank high on masculinity are more likely to consider sin stock investments than countries in feminine countries and thereby decreases the development of excess sin stock returns. 
Table 12 Results when including dummy variables for religion using equation 4 to calculate the alphas.

\begin{tabular}{|c|c|c|c|}
\hline Variables & (1) All & (2) ypothesized & (3) Without INDIV \\
\hline ALPHA_2 & $\begin{array}{l}3.679 \\
(0.138)\end{array}$ & $\begin{array}{l}3.093^{* *} \\
(0.037)\end{array}$ & $\begin{array}{l}3.202^{* *} \\
(0.022)\end{array}$ \\
\hline PDI & $\begin{array}{l}-0.012 \\
(0.355)\end{array}$ & & \\
\hline INDIV & $\begin{array}{l}-0.004 \\
(0.725)\end{array}$ & $\begin{array}{l}0.003 \\
(0.719)\end{array}$ & \\
\hline MAS & $\begin{array}{l}-0.018 \\
(0.135)\end{array}$ & $\begin{array}{l}-0.023^{* *} \\
(0.035)\end{array}$ & $\begin{array}{l}-0.022^{* *} \\
(0.024)\end{array}$ \\
\hline UA & $\begin{array}{l}-0.017 \\
(0.216)\end{array}$ & $\begin{array}{l}-0.010 \\
(0.367)\end{array}$ & $\begin{array}{l}-0.012 \\
(0.260)\end{array}$ \\
\hline LTO & $\begin{array}{l}0.008 \\
(0.534)\end{array}$ & & \\
\hline INDUL & $\begin{array}{l}-0.12 \\
(0.549)\end{array}$ & $\begin{array}{l}-0.018 \\
(0.155)\end{array}$ & $\begin{array}{l}-0.016 \\
(0.137)\end{array}$ \\
\hline Protestant & $\begin{array}{l}-0.522 \\
(0.340)\end{array}$ & $\begin{array}{l}-0.127 \\
(0.750)\end{array}$ & $\begin{array}{l}-0.115 \\
(0.762)\end{array}$ \\
\hline Orthodox & $\begin{array}{l}0.373 \\
(0.528)\end{array}$ & $\begin{array}{l}0.113 \\
(0.825)\end{array}$ & $\begin{array}{l}0.136 \\
(0.779)\end{array}$ \\
\hline Islam & $\begin{array}{l}0.203 \\
(0.781)\end{array}$ & $\begin{array}{l}0.254 \\
(0.699)\end{array}$ & $\begin{array}{l}0.118 \\
(0.817)\end{array}$ \\
\hline Buddhist & $\begin{array}{l}-1.755 \\
(0.190)\end{array}$ & $\begin{array}{l}-1.127 \\
(0.283)\end{array}$ & $\begin{array}{l}-1.307 \\
(0.143)\end{array}$ \\
\hline Chinese Folk Religions & $\begin{array}{l}-0.648 \\
(0.482)\end{array}$ & $\begin{array}{l}-0.260 \\
(0.754)\end{array}$ & $\begin{array}{l}-0.372 \\
(0.614)\end{array}$ \\
\hline Hindu & $\begin{array}{l}0.025 \\
(0.975)\end{array}$ & $\begin{array}{l}-0.064 \\
(0.934)\end{array}$ & $\begin{array}{l}-0.080 \\
(0.914)\end{array}$ \\
\hline Shinto & $\begin{array}{l}0.951 \\
(0.328)\end{array}$ & $\begin{array}{l}1.381 \\
(0.107)\end{array}$ & $\begin{array}{l}1.348^{*} \\
(0.096) \\
\end{array}$ \\
\hline
\end{tabular}

\section{Conclusion}

Numerous studies previously established that sin stocks have different characteristics compared to other stocks. However, previous research that examines sin stocks has generally assumed that countries are similar in their stance towards sin stocks or that other nations are similar to the US and have some disapproval of sin stocks. This study introduces a new model and shows that sin stocks are treated differently amongst nations depending on its culture and religion. The relationship that is analyzed throughout this study is that between different cultural values of countries as measured by Hofstede and the excess return of sin stocks is. The sample to answer this problem consists of 361 firms in 21 countries that are dispersed geographically. The industries included are classified using ICB codes 2717 (defense), 3533 (brewers), 3535 (distillers \& vintners), 3785 (tobacco), and 5752 (gambling). When analyzing this question using the CAPM, the outperformance of the sin stocks in this sample is $0.5 \%$, significant at a $1 \%$ level. When regressing the excess returns against the dimensions of Hofstede, the dimensions masculinity versus femininity and indulgence versus restraint have negative coefficients that are significant at a $5 \%$ level. This implies that when nations are considered more masculine, i.e. they are not expected to take care of anyone but themselves, they are more likely to invest in sin stocks. On the contrary, their feminine counterparts who put an emphasis on relationships, diffidence and caring for the weak are more likely to refrain from investing in sin stocks. When a country scores high on indulgence, i.e. it gives in to the urges of individuals and allows a rather liberal fulfillments of basic human needs, it

Do different cultural values affect the excess return of sin stocks 
is more likely to invest in sin stocks, whereas countries that score high on restraint, i.e. countries that suppress this fulfillment of basic human drives and makes sure its individuals do not give in to these urges by the establishment of strict social norms, are more likely to refrain from investing in sin stocks. This implies that countries with a high degree of masculinity, such as Japan and the Philippines have lower excess returns relative to countries with a high degree of femininity, such as Sweden and Bulgaria. Additionally, countries that are considered to score high on indulgence, such as the United Kingdom and the United States have on average a lower excess return compared to countries that score high on restraint, such as Hong Kong and Russia. A possible explanation as to why the dimension of individualism versus collectivism does not have an influence on the excess return of sin stocks might be the behavior that results from herding and groupthink. If the sample includes countries that have societal norms that result in the same behavior as what the majority of people invest in in collectivistic countries, then this results in the same behavior in both collectivistic and individualistic countries. When using the threefactor model the outperformance of sin stocks is still $0.5 \%$ significant at a $1 \%$ level. The dimensions that have a significant effect on the excess return of sin stocks are the same as found when using the CAPM; the interpretation therefore remains equivalent. When controlling for religion masculinity versus femininity remains significant and the same conclusion can be drawn. However, indulgence versus restraint is no longer significant. On a theoretical level, the results add to the existing literature by showing that the culture of a country has an influence on the excess return of sin stocks. The results show that culture can be seen as a further clarifying force for these abnormal sin stock returns. On a practical level, understanding the influence that culture has on equity valuations is important because of the large size of these industries worldwide, and the possibility that the level of the influence of culture is consequential. The results might change the decision of a firm on whether or not to finance using debt or equity in a certain country. Financing using equity is in most cases probably not as attractive as financing with debt in a country that is feminine and restraint as classified by Hofstede. The results demonstrate the importance of taking the disparities concerning culture between nations into consideration and the distortions in specific sin stock return created by these differences. Additionally, a firm might decide to go public in one country, but not in another country, because of the differences in the cost of equity caused by the reluctance to invest in sin stocks, thereby causing the increase in excess returns. Finally, a practical implication is that investors might better understand their behavior or take advantage of the behavior of investors in other countries. An investor from Germany does not benefit from investing in domestic sin stocks according to this research, however if he would invest in sin stocks listed on the Swedish stock market, he might benefit from the excess sin stock returns.

\subsection{Limitations and further recommendations}

The first limitation of this thesis is the built-in bias created by the methods used. There has been a large amount of criticism on the CAPM, as well as on the three-factor model. Although there is no perfect model, a recommendation for future research would be to consider the method of estimation, for example using the four-factor model by Carhart instead of the CAPM and the three-factor model. Another limitation is that the survivor bias has not been taken into consideration. All the firms in the sample are firms that are still tradable on the market today. Furthermore, firms that have been merged are only incorporated in the sample as an inclusion of another firm with which it has merged or it has not been included if it has merged with a firm that is not classified as ICB code 2717, 3533, 3535, 3785, or 575. Furthermore, when making the SMB and HML portfolios for the three-factor model, the assumption of integrated markets is made. The SMB and HML portfolios calculate the values for all countries together

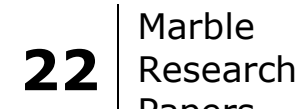 \\ Papers}


per year. A different, more detailed approach would have been to make these portfolios for each country separately. Due to time constraints and the depth of this thesis, this has not been done. Currently, there are 180 different values resulting from making the portfolio (30 years, 6 portfolios per year), whereas there would have 3780 different values when accounting for the 21 different countries. A recommendation for further research would be to investigate if there is a difference in results when religion is included per year, since in this paper the focus is laid upon the major religions in countries how they are at the moment, thereby making the assumption of constant time. There might have been changes in the last 30 years. Finally, the model of Hofstede does not account for changes in cultures and thereby assumes constant time. It might be worthwhile to investigate whether there are changes in the results if the values of Hofstede are included as two portfolios using dummy variables (for example: collectivistic vs. individualistic) instead of gradations, as have been used in this paper (for example: the dimension collectivistic vs. individualistic can be anywhere between 0 and 100), although this approach still does not account for the built-in bias of Hofstede due to the constant-time assumption. 


\section{References}

Ahrens, D. (2004). Investing in vice: The recession-proof portfolio of booze, bets, bombs \& butts. New York, NY: St. Martin's Press.

Akerlof, G., (1980). A theory of social custom, of which unemployment may be one consequence. Quarterly Journal of Economics, 94 (4), 749-775.

Arbel, A., Carvell, S., \& Strebel, P. (1983, May). Giraffes, institutions and neglected firms. Financial Analysts Journal, 39 (3), 57-63.

Armstrong, F. (2013, May 23). Rama-French Three Factor Model. Forbes. Retrieved from http://www.forbes.com/sites/frankarmstrong/2013/05/23/fama-french-three-factor-model/

Berk, J., \& DeMarzo, P. (2011). Corporate Finance (2nd ed.). Harlow, England: Pearson Education Limited.

Bikhchandani S. \& Sharma S. (2000). Herd Behavior in Financial Markets: A review (No. 48). Working Paper International Monetary Fund. Retrieved from https://www.imf.org/External/Pubs/FT/staffp/2001/01/pdf/Bikhchan.pdf

Boyd, R., \& Richerson, P. R. (1988). Culture and the Evolutionary Process. London, United Kingdom: The University of Chicago.

Charles, J. (2014, November 15). Savers turn to 'sin stocks' in search of higher return for their cash. The Guardian. Retrieved from http://www.theguardian.com/money/2014/nov/15/savers-higherreturn-cash-blue-chip

Clark, T. R., \& Clanton, D. W. (2012). Understanding religion and popular culture. Abingdon, England: Routledge.

Culture (n.d.). In Oxford English Dictionary. Retrieved from: http://www.oed.com

De Jong, E. \& R. Semenov. 2006. Cultural Determinants of Ownership Concentration across Countries. International Journal of Business Governance and Ethics, 2(1): 145 - 65.

Deresky, H., \& Christopher, E. (2012). International management: Managing cultural diversity (2nd ed., pp. 112-113). Sydney, Australia: Pearson Australia.

Diaz, J.D., 2000. Religion and gambling in sin-city: a statistical analysis of the relationship between religion and gambling patterns in Las Vegas residents. Social Science Journal, 37, 453-458.

Durand, R. B., Koh, S., \& Limkriangkrai, M. (2013, April). Saints versus sinners. Does morality matter? Journal of International Financial Markets, Institutions \& Money, 24, 166-183.

Durand, R. B., Koh, S., \& Tan, P. L. (2013). The price of sin in the Pacific-Basin. Pacific-Basin Finance Journal, 21(1), 899-913.

Ellison, C.G., Nybroten, K.A. (1999). Conservative Protestantism and opposition to state-sponsored lotteries: evidence from the 1997 Texas poll. Social Science Quarterly 80, 356-369.

Engs, R. C., \& Mullen, K. (1999, April). The effect of religion and religiosity on drug use among a selected sample of post-secondary students in Scotland. Addiction Research, 7 (2), 149-170.

Fama, E., and French, K. (1993). Common Risk Factors in the Returns on Stocks and Bonds. Journal of Financial Economics, 33(1), 3-56.

Fauver, L., \& McDonald, M. B. (2013, December 11). International variation in sin stocks and its effects on equity valuation. Journal of corporate finance, 25, 173-187

FTSE International Limited. (2010). A Single Standard Defining the Market. In Industry Classification Benchmark. Retrieved June 10, 2015, from http://www.icbenchmark.com

Giannetti, M., \& Yafeh, Y. (2012, February). Do cultural differences between contracting parties matter? Evidence from syndicated bank loans. Management Science, 58(2), 365-383. 
Groupthink (2009). In A Dictionary of Business and Management (5th ed.).

Hamilton, S., Jo, H. and Statman, M. (1993) Doing well while doing good? The investment performance of socially responsible mutual funds. Financial Analysts Journal, 49(6), 62-66.

Hoffman, J.P., 2000. Religion and problem gambling in the U.S. Review of Religious Research 41, 488509.

Hofstede, G. (n.d.). Cultural tools. In The Hofstede Centre. Retrieved from http://geerthofstede.com/countries.html

Hofstede, G. (1983). National cultures in four dimensions: A research-based theory of cultural differences among nations. International Studies of Management \& Organization, 13(1/2), 46-74

Hofstede, G., Hofstede, G., \& Minkov, M. (2010). Cultures and organizations: Software of the mind (3rd ed.). New York, NY: McGraw-Hill.

Hong H., and Kacperczyk M. (2009), The Price of Sin: the Effects of Social Norms on Markets, Journal of Financial Economics, 93 (1), 15-36.

Humphrey, J. E., \& Tan, D. T. (2013, May 15). Does it really hurt to be responsible? Journal of business ethics, 122(3).

Khan, M. Y., \& Jain, P. K. (2008). Financial Management (5th ed.). New Delhi, India: Tata McGraw-Hill.

Kim, I., \& Venkatachalam, M. (2011). Are Sin Stocks Paying the Price for Accounting Sins? Journal of accounting, auditing \& finance, 26(2), 415-442.

Levy, H. (2012). The capital asset pricing model in the 21st century: analytical, empirical, and behavioral perspectives. New York, NY: Cambridge University Press.

Licht, A. N., Goldschmidt, C., \& Schwartz, S. H. (2005). Culture, Law, and Corporate Governance. International Review of Law and Economics, 25, 229-255.

Mackintosh, J., \& Authers, J. (2015, February 10). Sin stocks pay as alcohol and cigarettes beat sober rivals. Financial Times. Retrieved from http://www.ft.com/intl/cms/s/0/78609b84-b147-11e4831b-00144feab7de.html\#axzz3VR5wyqEU

McKee, A., Kemp, T., \& Spence, G. (2013). Management: A focus on leaders (p. 454). Sydney, Australia: Pearson.

Merton, R. C. (1987, July). A Simple Model of Capital Market Equilibrium with Incomplete Information. The journal of finance, 42 (3), 483-510.

Money Management. 2006. Weapons and Dice, and All Things Vice 1 (June 1).

Murray, E. (2011, March 28). Religion: Countries Compared. In NationMaster. Retrieved June 25, 2015, from http://www.nationmaster.com/country-info/stats/Religion/Religions

Ostwalt, C. (2012). Secular Steeples: Popular Culture and the Religious Imagination (2nd ed.). Harrisburg, PA: Trinity Press International.

Paul, J. (2011). International Business (5th ed., pp. 153-154). New Delhi, India: PHI Learning Private Limited.

Poljak, V. (2015, February). Vice stocks yield higher returns than ethical stocks: report. The Sydney Morning Herald. Retrieved from http://www.smh.com.au/business/vice-stocks-yield-higherreturns-than-ethical-stocks-report-20150211-13bi51.html

Prosser, M., \& Sitaram, K. (1999). Civic discourse: Intercultural, international, and global media Vol. 2, p. 411). Stamford, CT: Ablex Publishing Corporation.

Do different cultural values affect the excess return of sin stocks 
Salaber, J. (2007). The Determinants of Sin Stock Returns: Evidence on the European Market. Working Paper.

Salaber, J. (2013, July 13). Religion and returns in Europe. European Journal of Political Economy, 32, 149-160. doi: 10.1016/j.ejpoleco.2013.07.002

Saroglou, V., \& Cohen, A. B. (2011, November). Psychology of Culture and Religion. Journal of CrossCultural Psychology, 42(2), 1309-1319.

Schneider, S. C., \& De Meyer, A. (1991, May). Interpreting and Responding to Strategic Issues: The Impact of National Culture. Strategic Management Journal, 12(4), 307-320.

Sharpe, N., De Veaux, R. D., \& Velleman, P. (2011). Business Statistics (2nd ed.). Toronto, Canada: Pearson Education.

Sin (n.d.). In Oxford English Dictionary. Retrieved from: http://www.oed.com

Social Investment Forum (2007). 2007 Report on Socially Responsible Investing Trends in the United States. Washington, DC: U.S. Retrieved from: http://www.ussif.org/files/Publications/07_Trends_\%20Report.pdf

Statman, M. (2000), Socially Responsible Mutual Funds, Financial Analysts Journal, 56 (3), 30-39.

Stevenson, T. (2015, February 14). Face facts: there's money in sin. The Telegraph. Retrieved from http://www.telegraph.co.uk/finance/comment/11413183/Face-facts-theres-money-in-sin.html

Stulz, R.M., and Williamson, R. (2003), Culture, Openness and Finance, Journal of Financial Economics, 70 (3), 313-349.

Tadesse, S., \& Kwok, C. (2005). National Cultural \& Financial Systems (Working Paper 884). Michigan, MI: The William Davidson Institute.

Teoh, S., Welch, I., Wazzan, C., 1999. The effect of socially activist investment policies on the financial markets: evidence from the South African boycott. Journal of Business, 72, 35-89.

USA Mutuals. (2014, December 31). Barrier Fund. In USA Mutuals. Retrieved from http://www.usamutuals.com

Waxler, C. (2004). Stocking up on sin: How to crush the market with vice-based investing (pp. 103114). Hoboken, NJ: John Wiley \& Sons, Inc.

Williams, G., \& Zinkin, J. (2008, April). The effect of culture on consumers' willingness to punish irresponsible corporate behaviour: applying Hofstede's typology to the punishment aspect of corporate social responsibility. Business Ethics, 17(2), 210-226.

Witzel, M., \& Varner, M. (2013). The Oxford Handbook of Management Theorists. Oxford, United Kingdom: Oxford University Press

World Bank. (2011). World databank. [Custom graph of data]. Retrieved from http://data.worldbank.org/indicator/MS.MIL.XPND.GD.ZS

Yeow, G. E. (2015, February 25). 'Sin' stocks make good buys. AsiaOne. Retrieved from http://business.asiaone.com/news/sin-stocks-make-good-buys

Zweig, J. (2015, February 13). 'Sin-Vestors' Can Reap Smoking-Hot Returns. The Wall Street Journal. Retrieved from http://www.wsj.com/articles/sin-vestors-can-reap-smoking-hot-returns1423874208

\footnotetext{
26 Research Papers
} 